\title{
PEMANFAATAN BAYAM HIJAU SEBAGAI UPAYA MENCEGAH ANEMIA PADA IBU HAMIL
}

\author{
Tri Restu $\mathbf{H}^{1}$, Susmita ${ }^{2}$ \\ 1,2 Sekolah Tinggi Ilmu Kesehatan Bina Husada Palembang \\ ${ }^{1}$ restu_senja@ymail.com, ${ }^{2}$ susmitasuharno@yahoo.co.id
}

\begin{abstract}
ABSTRAK
Anemia merupakan permasalahan kesehatan yang masih terjadi pada ibu hamil. Berdasarkan Riskesdas tahun 2018 angka anemia kehamilan yaitu sebesar 48,9\%, angka ini menunjukkan peningkatan jika dibandingkan dengan hasil Riskesdas tahun 2013 yaitu sebesar 37,1\%. Jenis anemia yang sering diderita ibu hamil adalah anemia defisiensi zat besi. Salah satu alternatif untuk memenuhi kebutuhan zat besi dapat dilakukan dengan mengkonsumsi sayuran yang mengandung zat besi, antara lain yaitu bayam hijau (Amaranthus). Kandungan zat besi pada bayam berperan untuk pembentukan haemoglobin. Tujuan pengabdian masyarakat ini adalah untuk meningkatkan pengetahuan ibu hamil tentang manfaat bayam hijau. Metode yang dilakukan yaitu penyuluhan dan pembagian bayam hijau bagi peserta penyuluhan. Hasil yang diperoleh dalam kegiatan ini adalah para ibu hamil mengetahui manfaat bayam hijau dan bersedia untuk mengkonsumsi bayam hijau sebagai upaya pencegahan anemia. Pengembangan program pengabdian masyarakat lebih optimal dengan integrasi program kesehatan ibu hamil, dinas dan pemerintah terkait yang dilakukan secara berkala dan berkelanjutan.
\end{abstract}

Kata kunci : Anemia, Bayam Hijau

\begin{abstract}
Anemia is a health problem that still occurs in pregnant women. Based on the 2018 Riskesdas, the pregnancy anemia rate was $48.9 \%$, this figure showed an increase when compared to the 2013 Riskesdas results, which was $37.1 \%$. The type of anemia that is often suffered by pregnant women is iron deficiency anemia. One alternative to meet iron needs can be done by consuming vegetables that contain iron, such as green spinach (Amaranthus). The iron content in spinach plays a role in the formation of hemoglobin. The purpose of this community service is to increase the knowledge of pregnant women about the benefits of green spinach. The method used is counseling and distribution of green spinach for counseling participants. The results obtained in this activity are pregnant women know the benefits of green spinach and are willing to consume green spinach as an effort to prevent anemia. The development of community service programs is more optimal with the integration of health programs for pregnant women, related agencies and government which are carried out regularly and continuously.
\end{abstract}

Keywords : Anemia, Green Spinach 


\section{PENDAHULUAN}

Anemia merupakan permasalahan kesehatan pada ibu hamil yang masih terjadi sampai saat ini. Berdasarkan data World Health Organisation (WHO) angka kejadian anemia di Asia sebesar 48,2\%. Sementara prevalensi anemia kehamilan di Indonesia berdasarkan Riskesdas 2018 yaitu sebesar 48,9\%. Angka ini menunjukkan peningkatan jika dibandingkan dengan hasil Riskesdas tahun 2013 yaitu sebesar 37,1\% .

Hasil penelitian Chi, dkk tahun 2013 menunjukkan bahwa angka kematian ibu adalah $70 \%$ untuk ibu-ibu yang anemia dan $19,7 \%$ untuk ibu yang non- anemia. Kematian ibu 15-20\%secara langsung atau tidak langsung berhubungan dengan anemia. Anemia pada kehamilan juga berhubungan dengan meningkatnya kesakitan ibu ${ }^{2}$.

Ibu hamil rentan mengalami anemia defisiensi zat besi. Anemia defisiensi zat besi merupakan kondisi dimana tubuh ibu hamil kekurangan zat besi sehingga kadar hemoglobin mengalami penurunan. Ibu hamil dinyatakan anemia jika hemoglobin $(\mathrm{Hb})<$ $11 \mathrm{mg} / \mathrm{L}$. Penyebabnya adalah kekurangan zat besi, asam folat dan vitamin B12 dikarenakan asupan yang tidak adekuat atau ketersediaan zat besi yang rendah ${ }^{3}$.

Secara fisiologis tubuh ibu hamil mengalami banyak perubahan yang disebabkan oleh hormon kehamilan. Darah ibu hamil mengalami pengenceran (hemodilusi) akibat dari peningkatan volume plasma darah (hipervolemia) yang tidak diimbangi dengan peningkatan sel darah merah. Kondisi ini membuat darah menjadi encer dan kadar hemoglobin menurun ${ }^{4}$.

Upaya pemerintah dalam mengatasi anemia defisiensi besi ibu hamil yaitu terfokus pada pemberian tablet tambah darah $(\mathrm{Fe})$ pada ibu hamil ${ }^{5}$. Pemberian tablet $\mathrm{Fe}$ di Indonesia pada tahun 2014 sebesar $85,1 \%$.

Anemia defisiensi zat besi pada ibu hamil dapat diatasi dengan cara mengkonsumsi 60-120 mg Fe per hari dan meningkatkan asupan makanan sumber Fe, selain itu untuk mengatasi anemia perlu konsumsi bahan-bahan pangan sumber zat besi, diantaranya daging, hati, ikan, susu, yoghurt, kacang-kacangan, serta sayuran berwarna hijau .

Zat besi yang terkandung di dalam suplemen, jika dikonsumsi dalam dosis besar dan waktu yang lama dapat menyebabkan kerusakan pada lapisan usus, kelainan $\mathrm{pH}$ tubuh, syok dan kegagalan hati².

Salah satu alternatif untuk memenuhi kebutuhan zat besi dapat dilakukan dengan mengkonsumsi sayuran yang mengandung zat besi, antara lain yaitu bayam hijau (Amaranthus). Kandungan zat besi pada bayam berperan untuk pembentukan haemoglobin ${ }^{2}$. 
Bayam hijau memiliki manfaat baik bagi tubuh karena merupakan sumber kalsium, vitamin A, vitamin E, vitamin C, betakaroten dan serat. Kandungan mineral dalam bayam cukup tinggi, terutama Fe yang digunakan untuk mencegah anemia. Mineral lain yang juga terkandung dalam bayam adalah asam folat. Fe dan asam folat berperan dalam hal produksi dan ketersediaan darah ${ }^{8}$.

Hasil penelitian Rohmatika (2015) menunjukkan nilai $\mathrm{p}<0,05$ yang berarti bahwa pemberian ekstrak bayam hijau secara signifikan mempengaruhi perubahan kadar hemoglobin. Kandungan $\mathrm{Fe}$ alami yang terdapat pada bayam hijau yang dikonsumsi dengan pengolahan yang benar dan tepat akan meningkatkan kadar Hb ibu hamil ${ }^{9}$.

Hasil penelitian Umarianti (2017) menunjukkan bahwa bayam hijau segar memiliki kadar Fe 8,3 mg/100 gram bayam segar, hasil proses ekstraksi 3.500 gram serbuk bayam hijau kering dengan $14.000 \mathrm{ml}$ aquadest menghasilkan kadungan $\mathrm{Fe} 21 \mathrm{mg} / \mathrm{gr}^{10}$.

Penelitian Restu (2019) di Puskesmas Nagaswidak menunjukkan hasil bahwa mengkonsumsi bayam hijau dapat meningkatkan kadar $\mathrm{Hb}$ pada ibu hamil dengan anemia. Berdasarkan hasil penelitian ini maka penulis tertarik untuk melakukan pengabdian masyarakat dengan mensosialisasikan manfaat bayam hijau sekaligus membagikan bayam hijau kepada ibu hamil yang berada dalam wilayah kerja puskesmas Nagaswidak Palembang sebagai upaya mencegah anemia pada ibu hamil ${ }^{3}$.

\section{METODE}

Pengabdian masyarakat dilakukan di Puskesmas Nagaswidak Kelurahan 14 Ulu Palembang pada tanggal 12-15 Oktober 2021, dengan tahapan dan metode pelaksanaan sebagai berikut :

1. Sosialisasi dan Perijinan

Tahap awal yang harus dilakukan adalah sosialisasi dan perijinan kepada pihak puskesmas Nagaswidak untuk mendapatkan persetujuan waktu dan tempat, selanjutnya melakukan sosialisasi kepada pihak terkait untuk mengerakkan para ibu hamil untuk menghadiri sosialisasi manfaat bayam hijau dengan mengikuti protokol kesehatan.

2. Persiapan alat dan sarana serta media

Alat dan sarana yang dipersiapkan pada kegiatan ini adalah media penyuluhan antara lain power point dan laptop. 
3. Penyuluhan manfaat bayam hijau bagi ibu hamil.

Ibu hamil dikumpulkan dalam satu ruangan dengan memperhatikan protokol kesehatan. Penyuluhan diberikan sejelas - jelasnya dengan memberikan kesempatan bertanya bagi para peserta penyuluhan yang belum paham.

4. Proses evaluasi dilakukan kepada para peserta penyuluhan dilakukan dengan cara memberikan pertanyaan sesuai dengan materi penyuluhan yang telah diberikan.

5. Pembagian bayam hijau ke rumah ibu hamil yang tidak datang dalam penyuluhan.

\section{HASIL DAN PEMBAHASAN}

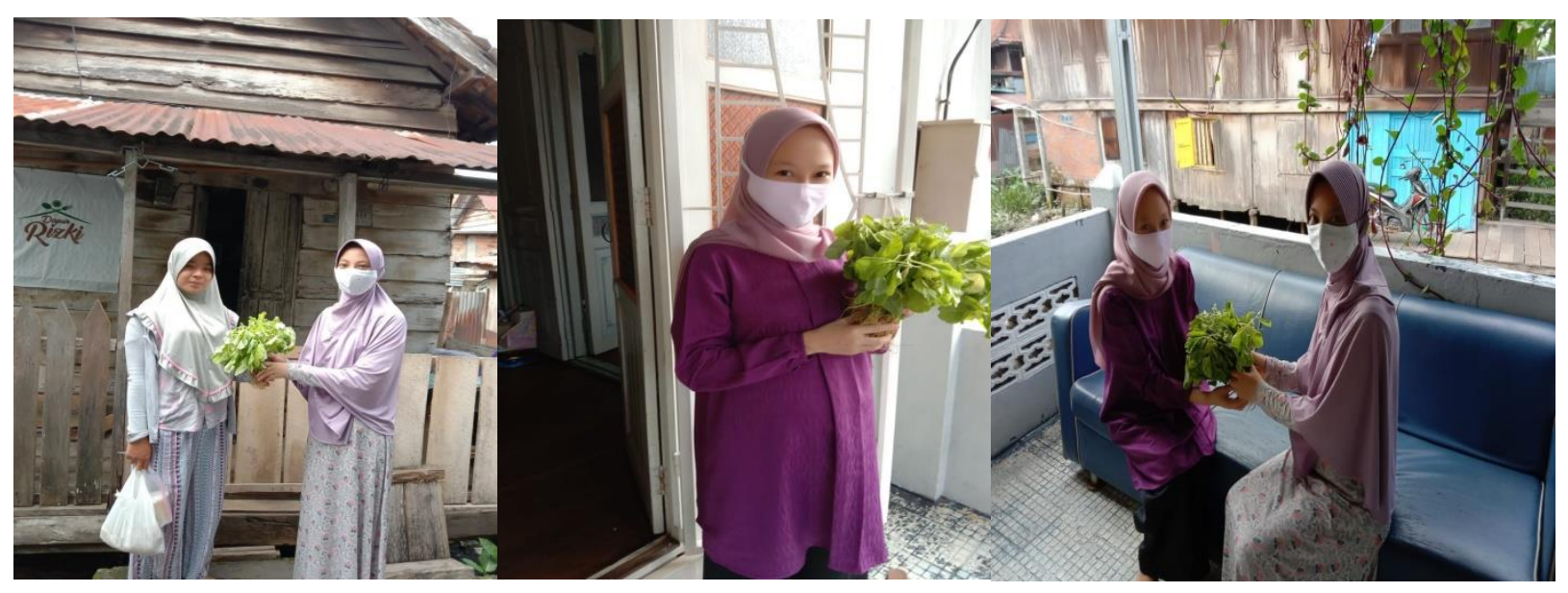

\section{Gambar 1}

\section{Pembagian Bayam Hijau Kepada Ibu Hamil Wilayah Kerja Puskesmas Nagaswidak Palembang}

Peserta mengikuti penyuluhan dengan semangat dan antusias. Peserta penyuluhan sebanyak 36 orang yang terdiri dari 28 ibu hamil dan 8 orang wanita usia subur yang sedang mempersiapkan kehamilan. Peserta datang tepat waktu dan memperhatikan protokol kesehatan. Penyuluhan berjalan lancar. Penggunaan media seperti laptop, LCD dan leaflet membantu peserta penyuluhan dalam memahami manfaat zat besi yang terkandung dalam bayam hijau yaitu sebagai upaya mencegah anemia pada ibu hamil. Materi juga disampaikan dengan sederhana menyesuaikan dengan tingkat pendidikan peserta penyuluhan. 
Beberapa ibu hamil menceritakan pengalaman hamilnya. Mereka mengatakan rutin mengkonsumsi tablet $\mathrm{Fe}$ yang diberikan oleh bidan pada saat kunjungan kehamilan sebagai upaya pencegahan anemia kehamilan. Namun beberapa ibu hamil merasakan efek samping mengkonsumsi tablet Fe yang cukup mengganggu seperti mual dan susah BAB. Berdasarkan pengalaman tersebut peserta penyuluhan merasa senang dengan kegiatan sosialisasi tentang manfaat bayam hijau ini. Bayam hijau bisa diolah menjadi makanan yang variatif seperti keripik bayam; bakso bayam; cake bayam; tanpa mengurangi kandungan zat besi di dalamnya.

Zat besi pada bayam hijau tidak hanya diperuntukkan pada ibu yang sedang mengandung, tetapi juga untuk para remaja yang rentan mengalami anemia, khususnya remaja yang baru mendapatkan haid. Penyuluhan dan pembagian bayam hijau juga bisa bermanfaat untuk mencegah anemia pada remaja.

Berdasarkan hasil evaluasi yang diberikan melalui post test didapatkan bahwa pengetahuan peserta penyuluhan tentang kandungan zat besi pada bayam hijau mengalami peningkatan sebesar $75 \%$ dibandingkan dengan hasil pretest yang dilakukan sebelum penyuluhan. Hasil kuesioner mengenai sikap ibu hamil terhadap konsumsi bayam hijau selama kehamilan sebagai upaya pencegahan anemia menunjukkan hasil yang positif, dimana ibu hamil menyetujui untuk mengolah bayam hijau agar menjadi makanan yang variatif, bernilai gizi tinggi dan bermanfaat untuk menambah zat besi di dalam tubuh.

\section{KESIMPULAN}

Sosialisasi dan edukasi tentang manfaat bayam hijau sebagai upaya mencegah anemia pada ibu hamil memberikan pengetahuan dan alternatif pemenuhan kebutuhan zat besi secara alami bagi para ibu hamil. Bayam hijau yang diberikan kepada ibu hamil dapat diolah menjadi makanan yang variatif untuk dikonsumsi. Saran untuk pihak Puskesmas agar dapat melaksanakan kegiatan ini secara rutin agar angka anemia pada ibu hamil dapat diturunkan.

\section{UCAPAN TERIMA KASIH}

Kami ucapkan terima kasih kepada warga dan pihak Puskesmas Nagaswidak yang telah bekerja sama dengan baik sehingga pengabdian masyarakat ini bisa berjalan dengan lancar dan bermanfaat.

\section{REFERENSI}

Agarwal KN, Gupta V, \& Agarwal S. (2013). Effect of Maternal Iron Status on Placenta, Fetus and Newborn.International journal of Medicine and Medical Sciences, 5(9), 5. 
Dinkes Kota Palembang. 2020. Data Dasar Kesehatan. www.dinkes.palembang.go.id

Kemenkes RI. 2020. Buku KIA. Jakarta : Kemenkes RI

Kemenkes RI. 2020. Data Dasar Puskesmas Propinsi Sumatera Selatan

Nasution,S. 2016. Analisa Kadar Besi (Fe) Pada Bayam Hijau Sesudah Perebusan Dengan Masa Simpan 1jam,3jam,5jam. Jurnal Ilmiah PANNMED.Vol 11.No 1.Medan.diakses 28

Restu, Tri dan Sartika. 2021. Buku Ajar Asuhan Kebidanan Kehamilan. Palembang : Noerfikri

Restu, Tri Handayani. 2017. Determinan Kejadian Anemia Defisiensi Zat Besi pada Ibu Hamil di Puskesmas Nagaswidak Palembang. Jurnal Masker Medika 5(2) 345-356, 2017

Retnorini, D. W, Widatiningsih S., dan Masini. 2017. Pengaruh Pemberian Tablet Fe dan Sari Kacang Hijau Terhadap Kadar Haemoglobin Ibu hamil. ejournal.poltekkessmg. ac.id/ojs/index.php/jurkeb.diakses 18 Maret 2018

Rizki, F. (2013) The Miracle Of Vegetables. cetakan pertama. Jakarta: PT Agromedia Pustaka

Rohmatika. 2015. Efektivitas Terapi Kombinasi Jus Bayam-Jeruk Sunkis-Madu Terhadap Kadar Hemoglobin Pada Ibu Hamil Dengan Anemia Di Wilayah Kerja Uptd Puskesmas Kecamatan Pontianak Selatan. jurnal.untan.ac.id/index.php/jmkeperawatanFK.diakses 18 Maret 2018 